\title{
A colaboração premiada como terceira via do direito penal no enfrentamento à corrupção administrativa organizada
}

\author{
Plea bargaining as a third route of criminal law in the \\ fight against organized administrative corruption
}

Marcelo Rodrigues da Silva ${ }^{1}$

LL.M ("Master of Laws") em andamento pela USP - Ribeirão Preto/SP. marcelordsadv@gmail.com

http://lattes.cnpq.br/0587339429201823

http://orcid.org/0000-0001-5224-4080

\begin{abstract}
Resumo: Este artigo tem por escopo examinar se os acordos de colaboração premiada celebrados no âmbito da Operação Lava Jato estão adotando um modelo de direito penal de terceira via no enfrentamento à corrupção administrativa, em que erige a reparação do dano como um dos objetivos primordiais da persecução penal, em substituição ou atenuação da pena restritiva de liberdade dos réus colaboradores. Posteriormente a esta análise, pretende-se refletir se a adoção de um direito penal de terceira via por meio destes instrumentos negociais poderia implicar em mercantilização utilitária do processo penal lesiva ao princípio da legalidade penal, da proporcionalidade e da isonomia na
\end{abstract}

1 Especialista em Ciências Criminais pela Universidade Estácio de Sá (UNESA). Master of Laws (LLM) em Direito Civil pela Universidade de São Paulo (USP) - 2015-2017. Especialista em Direito Contratual pela Pontifícia Universidade Católica de São Paulo (PUCSP). Especialista em Direito Público pela Escola Paulista da Magistratura (EPM). Especialista em Direito Público pelo Damásio de Jesus em convênio com a Universidade Potiguar. Autor do livro "Organizações Criminosas e Técnicas Especiais de Investigação" (Juspodivm) em coautoria com Luiz Flávio Gomes. Professor convidado na Pós-graduação em Ciências Criminais na Rede de Ensino LFG/Universidade Anhanguera-Uniderp. Professor em direito penal e processo penal na TV Justiça (Coordenada pelo Supremo Tribunal Federal). Professor do Portal Atualidades do Direito. Advogado. Representante do Instituto Brasileiro de Direito e Política de Segurança Pública nos anos 2012-2013. Membro associado do IBCCRIM, CONPEDI e do BRASILCON. 
aplicação da pena. Trata-se de uma análise necessária e pertinente em razão do protagonismo que os acordos de colaboração premiada vêm assumindo no descobrimento de grandes esquemas de corrupção no Brasil e na recuperação de ativos. A metodologia procedimental é a bibliográfica e o método de abordagem é o hipotético-dedutivo, além do estudo de caso envolvendo a Operação Lava Jato. A hipótese trabalhada é a de que os acordos de colaboração premiada vêm exteriorizando um direito penal de terceira via e que há com isso viabilidade de violações à legalidade penal, à proporcionalidade e à isonomia no enfrentamento à corrupção administrativa.

Palavras-Chave: Colaboração premiada; Terceira via do direito penal; Corrução Administrativa Organizada; Legalidade Penal; Proporcionalidade.

ABSTRACT: The purpose of this article is to examine whether the plea bargaining in the context of "Lava Jato" Operation is adopting a third route of criminal law against administrative corruption, in which reparation of damages is established as one of the primary objectives of criminal prosecution, in substitution or mitigation of the restrictive sentence of the collaborating defendants. Subsequent to this analysis, it is intended to reflect if the adoption of a third route of criminal law by means of these negotiating instruments could imply in the utilitarian mercantilization of the criminal process prejudicial to the principle of criminal legality, proportionality and isonomy in the application of the punishment. This is a necessary and pertinent analysis due to the protagonism that the plea-bargaining have been assuming in the discovery of great corruption schemes in Brazil and the recovery of assets. The procedural methodology is the bibliographic and the method of approach is the hypothetico-deductive one, besides the case study involving "Lava Jato" operation. The hypothesis worked out is that the award-winning collaboration agreements have externalized a third-way criminal law and that there is a viability of violations of isonomy and criminal legality in fight against administrative corruption.

KEYwoRDs: Plea-bargaining; Third route of criminal law; Administrative Corruption Organized; Criminal Legality; Proportionality.

SumárIO: Introdução. I. O cenário dos acordos de colaboração premiada no Brasil no enfrentamento à Corrupção Administrativa: Operação Lava Jato. II. A colaboração premiada e a terceira via do Direito Penal. III. Riscos da adoção da terceira via do direito penal nos acordos de colaboração premiada no enfrentamento à Corrupção; Considerações Finais. Referências. 


\section{INTRODUÇÃO}

O presente artigo tem por tema os acordos de colaboração premiada da Lei 12.850/2013 como instrumento de enfrentamento à corrupção administrativa e os riscos à legalidade, à proporcionalidade e à isonomia, mais especificamente no que tange ao âmbito da racionalidade da aplicação da pena, frente à eventual adoção por intermédio destes acordos de um modelo de direito penal de terceira via, em que erige a reparação do dano como um dos objetivos primordiais da persecução penal, em substituição ou atenuação da pena restritiva de liberdade dos réus colaboradores. O campo de observação adotado para o presente artigo é a Operação Lava Jato, que passou a ser pioneira na utilização dos acordos de colaboração premiada nos moldes da Lei 12.850/2013.

\section{O CENÁRIO dOS ACORdOS DE COLABORAÇÃo PREMIADA No BRASIL NO enfrentamento À CorrupÇão Administrativa: a Operação Lava Jato}

Os acordos de colaboração premiada da Lei 12.850/2013 - de influências anglo-saxã (de sistema common law, v.g.: plea bargaining norte-americana) e italiana (v.g: pattegiamento) - passaram a ser eficazes e principais aparatos no enfrentamento e repressão à Macrocriminalidade Econômica Organizada (do Colarinho-branco, White-Collar Criminality), a exemplo dos crimes de corrupção, crimes contra o sistema financeiro, crimes contra a ordem econômica, formação de organização criminosa, cartéis, lavagem de Dinheiro (Money Laundering), evasão de divisas etc. (crimes powerful).

A disfuncionalidade dos instrumentos probatórios tradicionais (v.g.: prova testemunhal, prova documental etc.), nas lições de Frederico Valdez Pereira, fez surgir um quadro de "estado de necessidade de investigação" - ou de "emergência investigativa" - apto a permitir as agências de repressão a utilizarem a justiça penal negociada (negócios jurídicos processuais ${ }^{2}$ ) para resolver o

2 Habeas Corpus 127.483, Supremo Tribunal Federal, Ministro Dias Toffoli. Disponível em: <http://www.stf.jus.br/arquivo/cms/noticiaNoticiaStf/anexo/HC127483relator.pdf>. Acesso em: 25 dez. 2016. 
bloqueio na apuração de determinados delitos complexos ou descobrir seus autores ${ }^{3}$.

No que tange especificamente à corrupção administrativa organizada (objeto do presente estudo), as causas das disfuncionalidades dos instrumentos probatórios tradicionais estão normalmente ligadas a alguns dos seus elementos característicos mais manifestos, quais sejam:

i) Complexidade do modus operandi, identificada: a) pela "profissionalização e pelo dinamismo da corrupção organizada"; b) pela utilização de meios tecnológicos sofisticados; c) pela transnacionalização ou internacionalização das condutas criminosas, em que a distância geográfica e os variados obstáculos legais ou burocráticos dificultam o trabalho investigativo do Estado; d) pelo cometimento de infrações não ostensivas, em que o principal agente criminoso e beneficiário da conduta delituosa atua de forma camuflada (autoria mediata, "homem de trás"), dando ordens e delegando funções executórias para outras pessoas de hierarquia inferior dentro de uma estrutura empresarial ou análoga; e) Forma consensual de atuação, a exemplo do que ocorre com os crimes de corrupção quid pro quo (é dando que se recebe)prática, segundo Hassemer, indispensável à criminalidade organizada (ao lado do clientelismo) ${ }^{5}$-, que é aquela caracterizada pelo suborno, "situações nas quais a criminalidade se apoderou dos braços que tinham missão de combate-la”, ou seja, quando o Legislativo, Executivo ou Judiciário tornam-se extorquiveis ou venais ${ }^{7}$. Ou seja, nestas situações em que não há conflito, mas sim há um acordo (um consenso) com rela-

3 PEREIRA, Frederico Valdez. Delação premiada. $2^{\mathrm{a}}$ ed. Curitiba: Juruá. 2014. p. 73-74.

4 ARAÚJO, Galucio Roberto Brittes de. Delação premiada, valor probatório e corrupção. In: ARAÚJO, Galucio Roberto Brittes; CUNHA FILHO, Alexandre J. Carneiro da; LIVIANU, Roberto; PASCOLATI JÚNIOR, Ulisses Augusto. 48 visões sobre a corrupção. São Paulo: Quarter Latim. 2016. p. 773.

5 VASCONCELOS, Carlos Eduardo de Oliveira. Dos Crimes Contra a Paz Pública. In: QUEIROZ, Paulo (Coord.) Direito Penal - parte especial. Vol. 2. $3^{\mathrm{a}}$ ed. Salvador: Juspodivm, 2016. p. 1082.

6 HASSEMER, Winfried. Perspectivas de Uma Nova Política Criminal. Trad. Adriana Beckman Meirelles. In: HASSEMER, Winfried. Direito Penal: fundamentos, estrutura, política. Porto Alegre: Sergio Antonio Fabris Editor, 2008. p. 311.

7 Idem. p. 268. 
ção à(s) conduta(s) criminosa(s), é notória, portanto, a dificuldade em se descobrir os delitos praticados, pois nestes casos há o ofuscamento dos ilícitos gerador de um quadro de não assimilação da ilicitude pelas vítimas em concreto, em especial pelo caráter essencialmente difuso dos bens penalmente protegidos; f) pela conexão entre organizações criminosas independentes, permitindo-se um cenário de cooperação, horizontalização e coordenação, em oposição à hierarquização, entre tais Organizações Criminosas, produzindo assim um relacionamento favorável entre elas próprias, e entre elas e o Poder Público, fornecedores e clientes, de forma a torná-las aceitas e fortalecidas nestas relações, bem como torná-las pouco percebidas pela sociedade; g) pela "penetração insidiosa no aparato governamental do Estado", "com a finalidade de obtenção de vantagens econômicas, financeiras, sociais ou penais, as quais possam beneficiar organizações criminosas" ${ }^{10}$, ou pela conexão da criminalidade com o Estado.

ii) Sofisticação estrutural, caracterizada pela: a) atuação dos agentes criminosos em moldes "quase empresariais"11, penetrandose no mundo dos negócios, facilitando com isso a ocultação ou dissimulação da natureza, origem, localização, disposição, movimentação ou propriedade de bens, direitos ou valores provenientes, direta ou indiretamente, de infração penal (lavagem de capitais); b) hierarquia das organizações criminosas, que vem sendo substituída pela atuação em redes de coordenação, com vinculação horizontal, gerando uma fragmentação do poder, o que dificulta ainda mais o seu conhecimento e repressão pelo Estado ${ }^{12}$;

8 VASCONCELOS, Carlos Eduardo de Oliveira. Dos Crimes Contra a Paz Pública. In: QUEIROZ, Paulo (Coord.) Direito Penal - parte especial. Vol. 2. $3^{\mathrm{a}}$ ed. Salvador: Juspodivm. 2016. p. 1077.

9 PEREIRA, Flávio Cardoso. Crime organizado e sua infiltração nas instituições governamentais. São Paulo: Atlas. 2015. p. 91.

10 Idem. p. 156.

11 BOTTINI, Pierpaolo Cruz. Enfrentamento de excessos não autoriza uso arbitrário das leis. 17 de outubro de 2013. Disponível em: <http://www.conjur.com. br/2013-out-17/pierpaolo-bottini-enfrentamento-excessos-nao-autoriza-uso-arbitrario-leis>. Acesso em 07 de fevereiro de 2017.

12 FERRO, Ana Luiza Almeida. Crime Organizado e Organizações Criminosas Mundiais. Curitiba: Juruá. 2009. p. 31. 
iii) Pacto de silêncio (omertà) entre seus membros.

A existência de um ou mais dos elementos acima, aliado(s) à falta de recursos destinados ao enforcement, impede que a notitia criminis chegue ao conhecimento das autoridades responsáveis pela persecução penal.

Assim, os negócios jurídicos premiais (acordos de colaboração premiada e de leniência), que deveriam se revestir de caráter excepcional ${ }^{13}$, vêm assumindo papel protagonista no desvendamento de casos de corrupção, a exemplo da Operação Lava Jato, "operação que revelou o maior caso de corrupção na história brasileira" ${ }^{14}$, quebrando o pacto do silêncio (omertà) existente no triângulo de corrupção baseado no capitalismo de laços ${ }^{15}$ "Políticos-Governo-Empreiteiras" (esquema assim denominado pelo réu e colaborador Paulo Roberto da Costa na Petição 5210 - STF ${ }^{16}$ ).

A colaboração premiada, como bem explicitou o Ministro do STF Celso de Mello: "possibilitou penetrar nesse grupo que se apoderou do Estado, promovendo um assalto moral, criminoso ao Erário

13 Paulo César Busato considera os acordos de colaboração premiada como "meios excepcionais de obtenção de provas" (BUSATO, Paulo César. As inovações da lei 12.850/13 e a atividade policial. In: AMBOS, Kai; MALARINO, Ezequiel; VASCONCELOS, Eneas Romerro (Coord.). Polícia e investigação no Brasil. Brasília: Gazeta Jurídica. 2016. p. 214).

14 NUNES, Leandro Bastos. Operação Lava Jato. Publicado em 01/2017. Disponível em: <https://jus.com.br/artigos/54880/operacao-lava-jato>. Acesso em: 03 jan. 2017.

15 Sérgio G. Lazzarini conceitua capitalismo de laços como "um modelo assentado no uso de relações para explorar oportunidades de mercado ou para influenciar determinadas decisões de interesse. Essas relações podem ocorrer somente entre atores privados, muito embora grande parte da movimentação corporativa envolva, também, governos e demais atores na esfera pública”. (LAZZARINI, Sérgio G. Capitalismo de Laços: Os donos do Brasil e suas conexões. Rio de Janeiro: Elsevier. 2011. p. 26).

16 Petição 5210 - Supremo Tribunal Federal (Relator Ministro Teori Zavaski), 24/09/2014. 9998683-14.2014.1.00.0000. Requerente Ministério Público Federal. Anexo 1 - Agentes Políticos- Triangulo Políticos-GovernoEmpreiteiras (página243). Disponível em: <http://politica.estadao. com.br/blogs/faustomacedo/wpcontent/uploads/sites/41/2015/03/ DELA\%C3\%87AO-PRC-01-a-23.pdf>. Acesso em: 24 dez. 2016. 
e desviando criminosamente recursos que tinha outra destinação, a destinação socialmente necessária e aceitável”17.

Para o Procurador da República e coordenador da força-tarefa da Operação Lava Jato, Deltan Dallagnol, a colaboração premiada funciona como "um guia, um catalisador, que otimiza o emprego de recursos públicos, direcionando-os para diligências investigatórias com maior perspectiva de sucesso". E continua o referido autor: "a colaboração é uma oportunidade para que o investigador espie por cima do labirinto e descubra quais são os melhores caminhos, isto é, aqueles com maior probabilidade de sucesso na angariação de provas" ${ }^{18}$.

Com o instrumento probatório da colaboração premiada os crimes de corrupção tornam-se mais facilmente elucidáveis, gerando esperanças populistas do aumento do papel dissuasório do direito penal com relação a estes crimes, haja vista que, para a escolha pela prática da conduta corrupta, tal fator (maior facilidade de elucidação) passaria a ser considerado pelo sujeito racional no cálculo dos custos e dos benefícios (dentro da equação elaborada por Gary Becker ${ }^{19}$ ), levando em conta a probabilidade dos autores destes crimes serem identificados, processados e punidos ${ }^{20}$.

17 FALCÃO, Márcio. Stf rejeita anular acordo de delação premiada de Youssef na Operação Lava Jato. Folha de São Paulo, 27 de agosto de 2105. Disponível em: http://www1.folha.uol.com.br/poder/2015/08/1674345-maioria-do-stfvota-contra-anulacao-de-depoimentos-de-alberto-youssef.shtml. Acesso em: 25 set. 2016. DALLAGNOL, Deltan. As luzes da delação premiada.

19 "The approach taken here follows the economists usual analysis of choice and assumes that a person commits an offense if the expected utility to him exceeds the utility he could get using his time and other resources at other activities. Some persons become 'criminal', therefore, not because their basic motivation differs from that of other persons, but because their benefits and costs differ" (BECKER, Gary. Crime and punishment -an economic approach. Journal of Political Economy. Vol 76. 1968. P. 176. Disponível em: <www.stor.org/stable/1830482>. Acesso em 07 de Janeiro de 2017).

20 BOTTINO, Thiago. Colaboração Premiada e incentivos à Cooperação no Processo Penal: Uma Análise Crítica dos Acordos Firmados na "Operação Lava Jato”. Revista Brasileira de Ciências Criminais, São Paulo, Ano 24, vol. 122, ago. 2016. p. 379. 
A midiatização ou espetacularização do sistema de justiça criminal ${ }^{21}$ popularizou a Operação Lava Jato, criando-se um estímulo ao Ministério Público Federal para a celebração de cada vez mais acordos de colaboração premiada a fim de encurtar o trabalho investigativo e apresentar à sociedade de forma célere um resultado (provisório) dos supostos autores do delito e das quantias astronômicas desviadas dos cofres públicos (que prometem ser repatriadas).

A inédita regulamentação normativa dos acordos de colaboração premiada trazida pela Lei $12.850 / 2013$ e a sólida perspectiva de punição para alguns dos réus investigados foram outros fatores que fortaleceram o uso do instrumento da colaboração premiada na Operação Lava Jato como forma de incentivo a colaborar com a justiça.

Foi desta forma que o instrumento probatório colaborativo premial que deveria ser excepcional tornou-se regra. Tanto é verdade que no âmbito da Operação Lava Jato, até a conclusão deste artigo (07 de janeiro de 2017), foram celebrados 71 acordos de colaboração premiada e 7 acordos de leniência ${ }^{22}$, sendo que 5 foram celebrados mesmo após a Polícia Federal no Paraná ter defendido a desnecessidade de novos acordos de colaboração premiada, pois na avaliação dos integrantes da Polícia Federal já havia sido recolhido material suficiente para apurações próprias sobre os esquemas de corrupção, sem precisar da ajuda de delatores, e a sensação de impunidade perante a sociedade iria aumentar caso mais acordos de colaboração fossem celebrados ${ }^{23}$.

Conforme informações prestadas em 19 de dezembro de 2016 pelo Ministério Público Federal, a Operação Lava Jato resultou em 1.434 procedimentos instaurados com 730 buscas e apreensões; 197

21 MENDES, Soraia da Rosa; BARBOSA, Kássia Cristina de Souza. Anotações sobre o requisito da voluntariedade e o papel do/a juiz/a em acordos de colaboração premiada envolvendo investigados/as e /ou réus/és presos/as provisoriamente. In: MENDES, Soraia da Rosa (org.). A delação/colaboração premiada em perspectiva. Brasília: IDP. 2016. p. 73.

22 Disponível em <http://lavajato.mpf.mp.br/atuacao-na-1a-instancia/resultados>. Acesso em 24 de dezembro de 2016.

23 MEGALEI, Bela. PF se opõe a novas delações premiadas na Lava Jato. São Paulo: Folha de São Paulo. 04 de Outubro de 2016. Disponível em: < http:// www1.folha.uol.com.br/poder/2016/10/1819588-pf-se-opoe-a-novas-delacoes-premiadas-na-lava-jato.shtml>. Acesso em: 07 jan. 2017. 
conduções coercitivas; 79 prisões preventivas; 103 prisões temporárias; 6 prisões em flagrante; 120 pedidos de cooperação internacional (sendo 98 pedidos ativos para 31 países e 22 pedidos passivos com 33 países); 56 acusações criminais contra 259 pessoas (sem repetição de nome), sendo que em 24 já houve sentença pelos crimes de corrupção, crimes contra o sistema financeiro internacional, tráfico transnacional de drogas, formação de organização criminosa, lavagem de ativos, entre outros; 7 acusações de improbidade administrativa contra 38 pessoas físicas e 16 empresas pedindo o pagamento de R\$12,5 bilhões. Até o momento em 120 condenações, contabilizando 1.257 anos, 2 meses e 1 dia de pena ${ }^{24}$.

Ainda conforme dados do Ministério Público Federal relacionados à Operação Lava Jato, cerca de $\mathrm{R} \$ 10,1$ bilhões são alvo de recuperação por acordos de colaboração, sendo $\mathrm{R} \$ 756,9$ milhões objeto de repatriação. $\mathrm{R} \$ 3,2$ bilhões de bens de réus já foram bloqueados ${ }^{25}$.

Como se verifica, viabilizou-se por meio dos acordos de colaboração premiada no âmbito da Operação Lava Jato a recuperação de significativas quantias subtraídas em razão dos ilícitos penais cometidos e o descobrimento de Organizações Criminosas infiltradas na Administração Pública direta e indireta (inclusive com atuação transnacional) e dos seus integrantes em virtude da quebra do pacto do silêncio (Omertà) que vige no âmbito destas Organizações Criminosas.

\section{A colaboração premiada e A terceira via do Direito Penal.}

Frente aos dados acima apresentados (em especial o fato de $\mathrm{R} \$$ 10,1 bilhões ser alvo de recuperação por acordos de colaboração, sendo R\$ 756,9 milhões objeto de repatriação, e as penas aplicadas a alguns dos réus colaboradores ilustradas no quadro), é possível deduzir que os acordos de colaboração premiada têm inclinações a um direito penal de terceira via, em que se erige a reparação do dano como um dos objetivos primordiais da persecução penal (fenômeno da "privatização do direito

\footnotetext{
24 Disponível em <http://lavajato.mpf.mp.br/atuacao-na-1a-instancia/resultados>. Acesso em: 24 dez. 2016. Idem.
} 
penal"26), em substituição ou atenuação da pena restritiva de liberdade dos réus colaboradores por meio de um contrato $^{27}$.

Do mesmo modo concluem Andreia Alves Almeida e Fabíola de Jesus Pereira que: "os Procuradores da República estão usando a colaboração premiada para recuperar valores que foram desviados da Petrobrás por meio da devolução espontânea pelos réus em troca de benefícios processuais, inclusive antes mesmo da fase judicial" ${ }^{28}$.

A base moderna do redimensionamento da resposta estatal frente aos delitos macroeconômicos nos acordos de colaboração premiada celebrados tem por combinação o sistema short-sharp -shock (prisão intensa e curta, mas efetivamente cumprida) com o sistema de reparação dos danos e o confisco de tudo que foi ganho ilicitamente ${ }^{29}$.

Segundo Luiz Flávio Gomes, "muito melhor que a fixação de uma pena de prisão (longa) inútil é a reparação dos danos em favor da vítima que, muitas vezes, o que só espera do sistema é a sua recomposição patrimonial. Fundamental também é o confisco do que foi ganho ilicitamente" ${ }^{30}$. Esta combinação de sistemas, de acordo com o referido autor, "atende às três finalidades que a melhor e mais atualizada doutrina atribui ao processo penal moderno: (a) retributivo-preventiva, (b) reparatória e (c) confiscatória”31.

26 GRECO, Rogério. Curso de Direito Penal - parte geral. Vol. 1. 18 a ed. Niterói: Impetus. 2016. p. 12.

27 “Delações premiadas são essencialmente contratos" (BROWN, Darryl. K. Free Market Criminal Justice: How Democracy and Laissez Faire Undermine the Rule of Law. New York: Oxford. 2016. - Livro Digital).

28 ALMEIDA, Andreia Alves de; PEREIRA, Fabíola de Jesus. A Eficácia da Colaboração Premiada no Combate à Corrupção: O Efeito Dominó na Operação Lava Jato. in: PRANDO, Camila Cardoso de Mello; STAFFEN, Márcio Ricardo; RIBEIRO, Diaulas Costa (Org.). Direito Penal e Constituição. Florianópolis: CONPEDI, 2016, p. 222.

29 GOMES, Luiz Flávio. A Impunidade da Macrodelinquência Econômica desde a Perspectiva Criminológica da Teoria da Aprendizagem. In: DOTTI, René Ariel; PRADO, Luiz Regis (Org.). Doutrinas essenciais de Direito Penal Econômico e da Empresa. Vol. I. São Paulo: Revista dos Tribunais. 2011. p. 643-644.

30 Idem.

31 Idem. 
Os malefícios relacionados com a corrupção administrativa são enormes, tanto para o indivíduo como para a sociedade, pois, segundo o "Relatório Corrupção: custos econômicos e proposta de combate" elaborado em março de 2010 pelo FIESP, atinge negativamente o desempenho econômico de um país, "na medida em que afeta as decisões de investimentos, limita o crescimento econômico, altera a composição dos gastos governamentais, causa distorções na concorrência, abala a legitimidade dos governos e a confiança no Estado"32.

Nesta esteira ganha relevo o enfoque da reparação do dano nos acordos de colaboração, em especial por induzir o comportamento colaborativo dos investigados, acusados ou condenados, o que, segundo Benjamin Tabak Miranda, "aumenta a chance de recuperação de recursos públicos desviados"33, e assim "a sociedade recupera ao menos parcialmente os recursos desviados, e os denunciantes, que propiciaram essa recuperação, recebem uma recompensa pelo esforço" 34 .

Leciona Claus Roxin que no direito penal de terceira via "a reparação substituiria ou atenuaria complementarmente a pena, naqueles casos nos quais convenha tão bem ou melhor aos fins da pena e às necessidades da vítima, que uma pena sem diminuição alguma" 35 .

Ou seja, pelas lições de Roxin, a reparação pode ser compreendida como uma sanção penal autônoma em substituição ou redução da pena privativa de liberdade, desde que tenha por aptidão alcançar os fins penais tradicionais das sanções (prevenção geral e especial). Não se pode olvidar que a reparação no direito penal tem, enquanto sanção

32 Disponível em: <http://www.fiesp.com.br/indices-pesquisas-e-publicacoes/ relatorio-corrupcao-custos-economicos-e-propostas-de-combate/>. Acesso em: 08 jan. 2017.

33 TABAK, Benjamin Miranda. A Análise Econômica do Direito - Proposições Legislativas e políticas públicas. Revista de Informação Legislativa / Senado Federal, Subsecretaria de edições Técnicas - Ano 52, n 205, jan./mar. 2015. p. 327.

34 Idem.

35 ROXIN, Claus. Fines de la pena y reparación del daño: de los delitos y de a las víctimas. Tradução española de Julio Maiery Elena Carranza. Buenos Aires: Ad Hoc, 1992, p. 155 (tradução livre). 
autônoma, um caráter misto, no qual mesclam elementos civis e penais, sendo que o caráter civil reside na compensação do dano, ao passo que o empenho do autor em cumprir com a reparação tem acepção jurídico-penal. Nestas linhas, Claus Roxin defende que a reparação do dano deverá desenvolver-se no âmbito das penas e das medidas de segurança como uma terceira via no direito penal ${ }^{36}$.

Na mesma esteira Ulfrid Neumann leciona que: "recentemente a introdução da relação autor-vítima-reparação no sistema de sanções penais nos conduz a um modelo de três vias, onde a reparação surge como uma terceira função da pena conjuntamente com a retribuição e a prevenção" ${ }^{37}$.

O princípio da subsidiariedade, segundo Roxin, justifica a adoção deste modelo de terceira via do direito penal. Ou seja, este princípio viria, assim, a legitimar a possibilidade de renunciar à pena, na medida em que fossem atendidas as suas finalidades preventivas por intermédio da realização de uma prestação positiva orientada à superação das consequências do delito, em que pese a existência da ameaça abstrata de pena ${ }^{38}$.

Ensina Cláudio Amaral do Prado, a partir das ideias de Claus Roxin, que:

O princípio da subsidiariedade estende sua operatividade além dos limites tradicionais em que se havia confinado como limite ao legislador, isto é, como pauta contenedora que incide sobre a decisão judicial a respeito da concreta reação penal. Logo, o juiz deve atuar com vistas às finalidades político-criminais do direito penal, tendo especialmente em conta a reparação ${ }^{39}$.

A inclinação do direito penal para um modelo sancionatório de reparação do dano em detrimento do encarceramento do crimino-

36 PRADO, Cláudio Amaral do. Despenalização pela reparação de danos: a terceira via. Leme: J.H. Mizuno, 2005, p. 166- 167

37 NEUMANN, Ulfrid. Alternativas al derecho penal (Critica e justificación del derecho penal en el cambio de siglo). El análisis crítico de la Escuela de Frankfurt. Cuenca: Editones de la Universidade de Castilla-La Mancha. 2003. p. 12.

PRADO, Cláudio Op. Cit. p. 166-167.

Idem. 
so foi até mesmo sustentada por Gary Becker ${ }^{40}$, ao afirmar que há um aumento do bem-estar social na medida em que as multas são usadas sempre que possível. ${ }^{41}$

Torna-se perceptível a opção pela análise econômica do direito (law and economics) na celebração dos acordos de colaboração premiada na Operação Lava Jato pelos Procuradores da República, pois, conforme informações prestadas pelo Ministério Público Federal, a concretização dos acordos leva em conta a análise dos custos e benefícios sociais, considerando variáveis tais como revelação dos crimes praticados e dos coautores, corroboração probatória do réu colaborador (provas que serão disponibilizadas), a relevância social dos fatos e das informações no contexto da investigação, a recuperação do proveito econômico auferido com os crimes, entre outras, sendo que o acordo só é celebrado quando os benefícios superarem significativamente os custos para a sociedade ${ }^{42}$.

A colaboração premiada nos moldes atuais segue a tendência de um direito penal do futuro, prenunciada por Winfried Hassemer, em que a vítima e a reparação dos danos são colocados no centro das concepções da teoria do Direito Penal e das Teorias da Pena ${ }^{43}$.

40 BECKER, Gary Stanley. The Economic Approach to Human Behavior. Universidade de Chicago Press. 1978. p. 63.

41 “[... ] social welfare is increased if fines are used whenever feasible. In the first place, probation and institutionalization use up social resources, and fines do not, since the latter are basically just transfer payments, while the former use resources in the form of guards, supervisory personnel, probation officers, and the offenders 'own time'" (BECKER, Gary Stanley. The Economic Approach to Human Behavior. Universidade de Chicago Press,1978. p. 63).

42 Disponível em: <http://lavajato.mpf.mp.br/atuacao-na-1a-instancia/investigacao/colaboracao-premiada>. Acesso em: 08 jan. 2017.

43 [...] um Direito Penal futuro levará (e deve levar) mais em consideração a vítima; há acentuações legais dos direitos de intervenção da vítima no processo penal, a reparação é um componente moderno e atrativo das teorias da pena, da determinação da pena e da práxis da execução penal, e em público a vítima sempre se manifesta de forma mais enérgica do que os político-criminais interessados. A teoria do Direito Penal e as teorias da Pena devem colocar a vítima mais no centro de suas concepções. Em todo caso, elas devem ter duas coisas em vista: impedir que a tensão dos polos entre as posições jurídicas sobre o autor e a vítima leve a um jogo de soma de zeros, no qual somente se pode dar a um aquilo que antes se retirou ao outro; e deixar claro que 
Integrou-se pela colaboração premiada o eficientismo na análise do justo, abandonando-se parcela de um efeito punitivo mais drástico (pena de prisão) em prol do efeito mais próximo do restaurativo (reparação do dano $)^{44}$.

\section{RISCOS DA ADOÇÃO DA TERCEIRA VIA DO DIREITO PENAL NOS ACORDOS DE COLABORAÇÃO PREMIADA NO ENFRENTAMENTO À CORRUPÇÃO}

Não se descarta a importância da reparação dos danos por meio dos acordos de colaboração premiada, mas este enquadramento da reparação dos danos a uma terceira via do direito penal traz riscos à legalidade penal, à proporcionalidade e à isonomia no campo da aplicação da pena.

A práxis ${ }^{45}$ vem demonstrando que os benefícios penais conferidos nos acordos de delação premiada aos colaboradores na Operação Lava Jato não se pautam por uma racionalidade minimamente adequada, vale dizer, inexistem critérios bem definidos para a concessão de prêmios, pois a Lei 12.850/2013 confere um rol de benefícios que autorizam - pelas vias interpretativas - que haja uma discricionariedade ex-

a vítima essencialmente mais ao centro da Política Criminal ingressará tão só como a pessoa lesada: ou seja, como qualquer um de nós (HASSEMER, Winfried. Desenvolvimentos previsíveis na dogmática do Direito Penal e na Política Criminal. Revista Eletrônica de Direito Penal e Política Criminal UFRGS, vol. 1, $\mathrm{n}^{\mathrm{o}}$ 1, 2013. p. 45-46).

44 AGUIAR, Júlio César de; FONSECA, Cibele Benevides Guedes da; TABAK, Benjamin Miranda. A colaboração premiada compensa?. Brasília: Núcleo de Estudos e Pesquisas/CONLEG/Senado. Agosto/2015 (Texto para Discussão $\left.n^{\circ} 181\right)$. Disponível em: <www.senado.leg.br/estudos>. Acesso em 08 de janeiro de 2017.

45 Veja-se a título de exemplo: a Petição 6138 -Acordo de Colaboração Premiada de Sérgio Machado (Disponível em: < http://estaticog1.globo. com/2016/06/15/PET-6138-Delacao-SergioMachado-VOLUME001.pdf>. Acesso em 07 de fevereiro de 2017), o Termo de Colaboração de Ricardo Ribeiro (Disponível em <http://politica.estadao.com.br/blogs/fausto-macedo/wp-content/uploads/sites/41/2015/09/397_ACORDO1.pdf> . Acesso em 07 de fevereiro de 2017); o Termo de Colaboração de Alberto Youssef (Disponível em: <http://politica.estadao.com.br/blogs/fausto-macedo/wpcontent/uploads/sites/41/2015/01/acordodela\%C3\%A7\%C3\%A3oyoussef. pdf $>$. Acesso em 07 de fevereiro de 2017). 
tremada ${ }^{46}$ pelo Ministério Público, em clara afronta ao princípio da legalidade penal, com previsão no artigo $5^{\circ}$, inciso XXXIX da Constituição Federal, que reza: "não há crime sem lei anterior que o defina, nem pena sem prévia cominação legal”.

A previsão normativa da Lei 12.850/2013 (Lei de Organizações Criminosas), que viabiliza que o colaborador que coopere de forma substancial possa não ter "pena alguma" 47 (artigo $4^{\circ}, \S 2^{\circ}$ da referida lei), ou, mais do que isto, não tenha "processo penal algum" contra $\mathrm{si}^{48}$ (artigo $4^{\mathrm{o}}$, $\S 4^{\mathrm{o}}$ da referida lei), vem sendo adotada pelo Ministério Público para justificar a oferta de reduções de pena a patamares superiores a de $2 / 3$, que seria a fração máxima de redução permitida pelo artigo $4^{\circ}$ da Lei $12.850 / 2013^{49}$, bem como regimes de cumprimento de pena não previstos em lei.

Isso se deve em razão da interpretação dada pelo Ministério Público lastreada na máxima a maiori, ad minus (o que é válido para o mais, deve necessariamente valer para o menos), vale dizer, se é possível o acordo de colaboração premiada tendo como prêmio o perdão judicial ou acordo de imunidade (o mais), seria possível o menos, que é a redução acima da fração máxima de $2 / 3$ da Lei 12.850/2013.

Segundo dados disponibilizados pela Justiça Federal e veiculados pela Folha de São Paulo ${ }^{50}$, ao final de 2015, vários dos réus colaboradores na Operação Lava em razão do cumprimento dos acordos de colaboração premiada tiveram por sentença drásticas reduções da pena. Veja-se tabela abaixo:

46 Eufemisticamente dizendo, pois se aproxima mais de uma arbitrariedade com respaldo legal.

47 Perdão judicial.

48 Acordos de Imunidade.

49 Caso a colaboração seja posterior à sentença, a pena poderá ser reduzida até a metade ou será admitida a progressão de regime ainda que ausentes os requisitos objetivos (artigo $4^{\circ}, \S 5^{\circ}$ da Lei 12.850/2013).

50 Disponível em: <http://economia.terra.com.br/pena-de-condenados-delatores-da-lava-jato-cai-de-283-para-7-anos-diz-folha,4432df60f91a44f45547686c51d03b7af7aj9ilp.html>. Acesso em: 08 mar. 2016. 
QUADRo 1. Comparação da pena aplicada e depois dos acordos de delação premiada no âmbito da Operação Lava-Jato.

\begin{tabular}{|c|c|c|c|}
\hline $\begin{array}{c}\text { Colaborador/ } \\
\text { Qualificação }\end{array}$ & $\begin{array}{c}\text { Pena fixada sem } \\
\text { redução pela } \\
\text { colaboração }\end{array}$ & $\begin{array}{l}\text { Pena negociada } \\
\text { (após prêmio da } \\
\text { colaboração) }\end{array}$ & $\begin{array}{l}\text { Quantias a título de } \\
\text { repatriação de valores } \\
\text { / multa }\end{array}$ \\
\hline $\begin{array}{l}\text { Alberto } \\
\text { Youssef } \\
\text { Doleiro }\end{array}$ & $\begin{array}{c}82 \text { anos e } 8 \\
\text { meses }\end{array}$ & $\begin{array}{c}3 \text { anos (regime } \\
\text { fechado) }\end{array}$ & $\begin{array}{l}\text { Renunciou em favor } \\
\text { da justiça vários bens } \\
\text { móveis ou imóveis, por } \\
\text { se tratarem de pro- } \\
\text { dutos e/ou proveitos } \\
\text { de crimes, bem como } \\
\text { quantia a quantia de } \\
\text { R\$ 1.893.410,00 (um } \\
\text { milhão, oitocentos e } \\
\text { noventa e três mil, } \\
\text { quatrocentos e dez } \\
\text { reais) e U\$ } 20.000,00 \\
\text { (vinte mil dólares } \\
\text { americanos) apreen- } \\
\text { didos nas dependên- } \\
\text { cias da empresa GFD } \\
\text { Investimentos Ltda }{ }^{51} \text {. }\end{array}$ \\
\hline $\begin{array}{l}\text { Augusto } \\
\text { Ribeiro de } \\
\text { Mendonça } \\
\text { Neto } \\
\text { Executivo } \\
\text { (Toyo Setal) }\end{array}$ & $\begin{array}{c}16 \text { anos e } 8 \\
\text { meses }\end{array}$ & $\begin{array}{c}4 \text { anos (regime } \\
\text { aberto) }\end{array}$ & $\begin{array}{l}\text { Comprometeu-se a } \\
\text { pagar a título de multa } \\
\text { compensatória cível } \\
\text { pelos danos que reco- } \\
\text { nhece causados o valor } \\
\text { de R } \$ 10.000 .000,00 \\
\text { (dez milhões) }^{52} \text {. }\end{array}$ \\
\hline
\end{tabular}

51 Disponível em: http://politica.estadao.com.br/blogs/fausto-macedo/wpcontent/uploads/sites/41/2015/01/acordodela\%C3\%A7\%C3\%A3oyoussef. pdf. Acesso em: 10 fev. 2017.

52 Inteiro teor do Acordo de Colaboração Premiada disponível em: http:// politica.estadao.com.br/blogs/fausto-macedo/wp-content/uploads/sites/41/2014/12/1_DECL68-contrato-dela\%C3\%A7\%C3\%A3o-augusto.pdf. Acesso em: 10 fev. 2017. 


\begin{tabular}{|c|c|c|c|}
\hline $\begin{array}{c}\text { Colaborador/ } \\
\text { Qualificação }\end{array}$ & $\begin{array}{c}\text { Pena fixada sem } \\
\text { redução pela } \\
\text { colaboração }\end{array}$ & $\begin{array}{l}\text { Pena negociada } \\
\text { (após prêmio da } \\
\text { colaboração) }\end{array}$ & $\begin{array}{l}\text { Quantias a título de } \\
\text { repatriação de valores } \\
\text { / multa }\end{array}$ \\
\hline $\begin{array}{l}\text { Dalton } \\
\text { Avancini } \\
\text { Executivo } \\
\text { (Camargo } \\
\text { Corrêa) }\end{array}$ & $\begin{array}{c}15 \text { anos e } 10 \\
\text { meses }\end{array}$ & $\begin{array}{l}3 \text { anos e } 3 \text { meses } \\
(3 \text { meses em } \\
\text { regime fechado, } \\
\text { com progressão) }\end{array}$ & $\begin{array}{l}\text { Comprometeu-se a pagar } \\
\text { uma multa de } \mathrm{R} \$ 2,5 \\
\text { milhões, dos quais } \mathrm{R} \$ \\
959 \text { mil já foram quitados } \\
\text { (eram os bens apreendi- } \\
\text { dos pela Polícia Federal) }\end{array}$ \\
\hline $\begin{array}{l}\text { Eduardo Leite } \\
\text { Executivo } \\
\text { (Camargo } \\
\text { Corrêa) }\end{array}$ & $\begin{array}{c}15 \text { anos e } 10 \\
\text { meses }\end{array}$ & $\begin{array}{l}3 \text { anos e } 3 \text { meses } \\
(3 \text { meses em } \\
\text { regime fechado, } \\
\text { com progressão) }\end{array}$ & $\begin{array}{l}\text { Devolução de R\$ } \\
3.234 .115,08^{54}\end{array}$ \\
\hline $\begin{array}{l}\text { Fernando } \\
\text { Baiano } \\
\text { Operador do } \\
\text { Esquema }\end{array}$ & $\begin{array}{c}16 \text { anos, } 1 \text { mês } \\
\text { e } 10 \text { dias }\end{array}$ & $\begin{array}{l}4 \text { anos ( } 1 \text { ano em } \\
\text { regime fechado, } \\
\text { com progressão) }\end{array}$ & $\begin{array}{l}\text { No acordo de colaboração } \\
\text { estipulou que perderá o } \\
\text { valor de R\$ } 8,5 \text { milhões } \\
\text { que foi bloqueado de sua } \\
\text { conta quando foi preso } \\
\text { na Operação lava Jato. } \\
\text { Ademais, desembolsará } \\
\text { mais R\$ } 5 \text { milhões e uma } \\
\text { casa que tem em Trancoso, } \\
\text { no litoral baiano. }\end{array}$ \\
\hline $\begin{array}{l}\text { Julio Gerin } \\
\text { de Almeida } \\
\text { Camargo } \\
\text { Lobista (Tovo } \\
\text { Setal) }\end{array}$ & 26 anos & $\begin{array}{c}5 \text { anos (regime } \\
\text { aberto) }\end{array}$ & $\begin{array}{l}\text { Comprometeu-se a pagar } \\
\text { a título de multa compen- } \\
\text { satória cível pelos danos } \\
\text { que reconhece causados o } \\
\text { valor de R\$ } 40.000 .000,00 \\
\text { (quarenta milhões) }\end{array}$ \\
\hline
\end{tabular}

53 Disponível em: http://www1.folha.uol.com.br/poder/2015/06/1643812juiz-homologa-delacao-de-executivo-da-camargo-correa-na-lava-jato.shtml . Acesso em: 10 fev. 2017..

54 Disponível em: http://www.em.com.br/app/noticia/politica/2016/11/18/ interna_politica,824946/forca-tarefa-da-lava-jato-anuncia-devolucao-de-r204-milhoes-desviado.shtml. Acesso em: 10 fev. 2017.

55 Disponível em: http://politica.estadao.com.br/blogs/fausto-macedo/wpcontent/uploads/sites/41/2015/01/1_DECL70-contrato-dela\%C3\% A7\%C3\%A3o-julio-gerin.pdf. Acesso em: 10 fev. 2017. 


\begin{tabular}{|c|c|c|c|}
\hline $\begin{array}{c}\text { Colaborador/ } \\
\text { Qualificação }\end{array}$ & $\begin{array}{l}\text { Pena fixada sem } \\
\text { redução pela } \\
\text { colaboração }\end{array}$ & $\begin{array}{l}\text { Pena negociada } \\
\text { (após prêmio da } \\
\text { colaboração) }\end{array}$ & $\begin{array}{l}\text { Quantias a título de } \\
\text { repatriação de valores } \\
\text { / multa }\end{array}$ \\
\hline $\begin{array}{l}\text { Mário Goes } \\
\text { Lobista }\end{array}$ & $\begin{array}{c}18 \text { anos e } 4 \\
\text { meses }\end{array}$ & $\begin{array}{c}3 \text { anos, } 5 \text { meses } \\
\text { e } 25 \text { dias ( } 25 \\
\text { dias em regime } \\
\text { fechado, com } \\
\text { progressão) }\end{array}$ & $\begin{array}{l}\text { Comprometeu-se a pa- } \\
\text { gar uma multa compen- } \\
\text { satória no valor de R\$ } \\
38 \text { milhões }^{56} \text {. }\end{array}$ \\
\hline $\begin{array}{c}\text { Nestor } \\
\text { Cerveró } \\
\text { Burocrata } \\
\text { (ex-diretor } \\
\text { internacional } \\
\text { da Petrobrás) }\end{array}$ & $\begin{array}{l}17 \text { anos, } 3 \text { me- } \\
\text { ses e } 10 \text { dias }\end{array}$ & $\begin{array}{c}3 \text { anos (regime } \\
\text { fechado e prisão } \\
\text { domiciliar) }\end{array}$ & $\begin{array}{l}\text { Comprometeu-se ao } \\
\text { pagamento de multa } \\
\text { compensatória de vários } \\
\text { valores, como por } \\
\text { exemplo o pagamento } \\
\text { imediato, à razão de } \\
\text { oitenta por cento para o } \\
\text { Petróleo Brasileiro S/A } \\
\text { e vinte por cento para a } \\
\text { União, mediante renún- } \\
\text { cia a todo e qualquer } \\
\text { direito e ação, de todos } \\
\text { os saldos nas contas } \\
\text { de fundos de investi- } \\
\text { mento e de previdência } \\
\text { privada PGBL, cujo } \\
\text { valor estima-se em R\$ } \\
825.000,00 \text { (oitocentos } \\
\text { e vinte e cinco mil) }\end{array}$ \\
\hline
\end{tabular}

56 Disponível em: http://g1.globo.com/pr/parana/noticia/2015/07/delacaode-mario-goes-na-lava-jato-preve-multa-de-r-38-milhoes.html . Acesso em: 10 fev. 2017..

57 Disponível em: http://d2f17dr7ourrh3.cloudfront.net/wp-content/uploads/2016/06/Cerver\%C3\%B3-vol-1.pdf. Acesso em: 10 fev. 2017. 


\begin{tabular}{|c|c|c|c|}
\hline $\begin{array}{c}\text { Colaborador/ } \\
\text { Qualificação }\end{array}$ & $\begin{array}{l}\text { Pena fixada sem } \\
\text { redução pela } \\
\text { colaboração }\end{array}$ & $\begin{array}{l}\text { Pena negociada } \\
\text { (após prêmio da } \\
\text { colaboração) }\end{array}$ & $\begin{array}{l}\text { Quantias a título de } \\
\text { repatriação de valores } \\
\text { / multa }\end{array}$ \\
\hline $\begin{array}{l}\text { Paulo Roberto } \\
\text { Costa } \\
\text { Burocrata } \\
\text { (ex-diretor de } \\
\text { abastecimento } \\
\text { da Petrobrás) }\end{array}$ & $\begin{array}{c}39 \text { anos e } 5 \\
\text { meses }\end{array}$ & $\begin{array}{l}2 \text { anos e } 6 \text { meses } \\
(6 \text { meses em } \\
\text { regime fechado, } \\
\text { com progressão) }\end{array}$ & $\begin{array}{l}\text { Renunciou, a título } \\
\text { de exemplo, em favor } \\
\text { da União, a qualquer } \\
\text { direito sobre valores } \\
\text { mantidos em contas } \\
\text { bancárias e investi- } \\
\text { mentos no exterior, em } \\
\text { qualquer país, inclusive } \\
\text { mantidos no Royal Bank } \\
\text { Of Canada Cayman, } \\
\text { aproximadamente USD } \\
2,8 \text { milhões sob os } \\
\text { nomes dos familiares } \\
\text { Márcio e Humberto), } \\
\text { e os aproximadamente } \\
\text { USD } 23 \text { (vinte e três) } \\
\text { milhões mantidos na } \\
\text { Suíça (em contas de } \\
\text { Marici, Paulo Roberto e } \\
\text { Arianna), controladas } \\
\text { direta ou indiretamen- } \\
\text { te, bem como valores } \\
\text { mantidos por meio de } \\
\text { offshores, etc. } \\
\text { Vários outros valores } \\
\text { comprometeu-se a pagar } \\
\text { a título de indenização } \\
\text { cível, pelos danos que } \\
\text { reconhece causados por } \\
\text { diversos crimes que } \\
\text { praticou. }{ }^{58}\end{array}$ \\
\hline
\end{tabular}

58 Disponível em: http://s.conjur.com.br/dl/acordo-delacao-premiada-paulo -roberto.pdf. Acesso em: 10 fev. 2017. 


\begin{tabular}{|c|c|c|c|}
\hline $\begin{array}{c}\text { Colaborador/ } \\
\text { Qualificação }\end{array}$ & $\begin{array}{c}\text { Pena fixada sem } \\
\text { redução pela } \\
\text { colaboração }\end{array}$ & $\begin{array}{c}\text { Pena negociada } \\
\text { (após prêmio da } \\
\text { colaboração) }\end{array}$ & $\begin{array}{c}\text { Quantias a título de } \\
\text { repatriação de valores } \\
\text { / multa }\end{array}$ \\
\hline $\begin{array}{c}\text { Pedro Barusco } \\
\text { Burocrata } \\
\text { (ex-gerente da } \\
\text { Petrobrás) }\end{array}$ & $\begin{array}{c}\text { meses } \\
\text { mono } 4\end{array}$ & $\begin{array}{c}2 \text { anos (regime } \\
\text { semiaberto) }\end{array}$ & $\begin{array}{l}\text { Comprometeu-se repa- } \\
\text { triar aproximadamente } \\
\text { US\$ 67.000.000,00 (ses- } \\
\text { senta e sete milhões) à } \\
\text { Petrobrás, assim como } \\
\text { para os fins do artigo 70 } \\
\S 11^{\circ} \text { da Lei 9.613/98, } \\
\text { com redação dada pela } \\
\text { Lei 12.683/12.59 }\end{array}$ \\
\hline
\end{tabular}

* Fonte das primeiras duas colunas da tabela (da esquerda para a direita): Folha de São Paulo, a partir de dados disponibilizados pela Justiça Federal, ao final de 2015. Os dados da última coluna foram obtidos em grande parte de fontes primárias (acordos de colaboração premiada celebrados).

Constata-se, portanto, que o Poder Judiciário ao homologar e sentenciar os acordos de colaboração premiada na Operação Lava Jato tem aceitado a interpretação conferida pelo Ministério Público e atuado com muita complacência ${ }^{60}$ com relação a estes acordos, principalmente no que concerne aos benefícios ofertados pelo órgão ministerial, aceitando o estabelecimento de prêmios contendo drásticas reduções de pena e regimes não previstos em lei.

Com relação a este comportamento complacente do Judiciário frente a tais acordos, certeira é advertência Vinicius Vasconcellos no sentido de que há uma "indevida usurpação das funções decisórias pelo acusador em razão de seu papel nevrálgico na determinação da culpabilidade e da pena ao imputado" ${ }^{\circ}$.

59 Disponível em: http://politica.estadao.com.br/blogs/fausto-macedo/wp-content/uploads/sites/41/2015/02/858_ANEXO2.pdf. Acesso em: 10 fev. 2017.

60 Sérgio Moro fala em "deferência" ao conceder os prêmios previstos nos acordos de colaboração premiada. Veja-se sua sentença na Ação Penal ${ }^{\circ}$ 508325829.2014.4.04.7000/PR, 13 ${ }^{\mathrm{a}}$ Vara Federal de Curitiba de 20 de Julho de 2015.

61 VASCONCELLOS, Vinicius Gomes de. Barganha e justiça criminal negocial. São Paulo: IBCCRIM. 2015. p. 215. 
A aludida interpretação conferida pelo Ministério Público (e avalizada pelo Judiciário) é reforçada por um discurso do direito penal de terceira via, pois em todos os acordos de colaboração listados na tabela acima existem cláusulas de multa compensatória e de repatriação de vultuosas quantias (veja-se por exemplo o acordo de Colaboração Premiada celebrado entre a força tarefa "Operação Lava Jato" do Ministério Público Federal e Pedro José Barusco Filho, em que este se compromete a depositar aproximadamente US\$ 67.500.000,00 em conta judicial aberta por ordem do juízo de homologação, o qual será destinado para o ressarcimento de eventuais danos sofridos pela empresa Petróleo Brasileiro S/A - Petrobrás ${ }^{62}$ ).

Denota-se, portanto, um discurso utilitário-economicista como tônica do processo penal relativo aos crimes de corrupção, que leva os órgãos de persecução e o Poder Judiciário a buscarem um resultado patrimonial no processo (mercantilização processual), atropelando-se a legalidade penal - caracterizada por regras imperativas e de aplicação obrigatória - e tornando a liberdade objeto de compra pelo colaborador, afinal: "O que o dinheiro não compra?”63, conforme questionaria Michael J. Sandel.

Não por outra razão, pertinente é a colocação de Renan Mandarino, no sentido de que "a liberdade se torna uma moeda de troca do acusado e transforma o sistema de justiça criminal num verdadeiro 'business', isto é, num mercado que se propõe a efetivar acordos 'rentáveis ao Estado" ${ }^{64}$.

Darryl Brown, em críticas à mercantilização do processo penal, afirma que:

Normas deontológicas como a imparcialidade judicial e o compromisso do Ministério Público com a justiça baseiam-se em valores e instituições fora do mercado. Mas as regras baseadas no mercado minam essas normas ao encorajar os participantes

62 Disponível em: <http://politica.estadao.com.br/blogs/fausto-macedo/wpcontent/uploads/sites/41/2015/02/858_ANEXO2.pdf> . Acesso em: 08 fev. 2017.

63 SANDEL, Michael J. O que o dinheiro não compra: os limites morais do mercado. Rio de Janeiro: Civilização Brasileira. 2012.

64 MANDARINO, Renan Posella. Aspectos penais controversos da colaboração premiada. São Paulo: IASP, 2016. p. 215. 
a celebrar delações premiadas como práticas instrumentais conduzidas por interesses partidários, e não como uma concessão de direito público comprometida com princípios públicos (como punição proporcional à culpa), critérios públicos para um processo justo e responsabilidade pública pela integridade das sentenças judiciais criminais ${ }^{65}$.

A amplíssima discricionariedade e a falta de fundamentação na concessão dos prêmios pelo Ministério Público somado à deferência do Judiciário frente a tais acordos descamba não raro para o terreno da arbitrariedade, que eleva os níveis de seletividade do direito penal. ${ }^{66} \mathrm{Ou}$ seja, surge com isso o risco de se criar uma justiça penal de classes econômicas ${ }^{67}$.

A falta de transparência com relação ao cálculo das reprimendas negociadas não cumpre com o espírito democrático exigido pelo princípio da legalidade, que impõe critérios objetivos de fixação da pena, de forma a reduzir arbitrariedades e tratamentos não isonômicos.

O sistema dosimétrico brasileiro de pena hoje vigente (sistema de penas "relativamente indeterminadas", nas lições de Eugênio

65 BROWN, Darryl. K. Free Market Criminal Justice: How Democracy and Laissez Faire Undermine the Rule of Law. New York: Oxford. 2016. - Livro Digital) (Tradução Livre).

66 A banalização do uso da delação termina(rá) culminando em punições brandas a um grande número de integrantes dos esquemas criminosos (inclusive com possibilidade de penas abaixo do mínimo legal previsto no preceito penal secundário ou regimes de cumprimento de pena não previstos em lei, como o caso do "regime domiciliar", ou até mesmo extinção da punibilidade), em evidente contraste com o "direito penal da classe marginalizada", "orientado pela chicotada" (direito penal mais rigoroso e sem espaço para o consenso) e "pela Súmula 231 do STJ, ou seja, a pena não pode baixar do mínimo pela confissão" (ROSA, Alexandre Morais da. Guia Compacto do Processo Penal Conforme a Teoria dos Jogos. Florianópolis: Empório do Direito. 2016. p. 295). Assim, com arrimo nas lições de Alexandre Moraes da Rosa, o acordo de colaboração premiada virou “'grande negócio' para rico, porque sem pudores, brada-se que [acordo de] 'delação premiada não é para pobre [ou sujeito estigmatizado]'” (Idem. p. 295).

67 SUMALLA, Josep M. Tamarit. La Reparación da la Víctima en el Derecho Penal (Estudio y Criítica de las Nuevas Tendencias Políticos-Criminales). Barcelona: Edición Centre d'Etudies Jurídicis i Formació Especializtada de la Generalitat de Catalunya \& Fundació Jaume Callís. 1993. p. 161. 
Zaffaroni e José Pierangeli ${ }^{68}$ ) está longe de ser perfeito, mas tem por virtude garantir, ainda que minimamente, um caminho para o juiz individualizar a pena, algo que não vem ocorrendo com relação aos acordos de colaboração premiada no enfrentamento à corrupção.

Não são convenientes reduções de pena em patamares observados na tabela acima, pois tais reduções podem ter como consequência a violação da legalidade e da isonomia na aplicação da lei penal.

Documentos internacionais ratificados pelo Brasil tratam da matéria, ressaltando a importância do enfrentamento a crimes de corrupção. Cite-se como exemplo: a) o artigo $3^{\circ}$, item 1 da Convenção da OCDE/1997 contra a Corrupção de Administrações Públicas Estrangeiras, que reza: “corrupção de um funcionário público estrangeiro deverá ser punível com penas criminais efetivas, proporcionais e dissuasivas"; b) o artigo 12, item 1 da Convenção das Nações Unidas contra a Corrupção, adotada pela Assembleia-Geral das Nações Unidas em 31 de outubro de 2003, que reza: "Cada Estado Parte, em conformidade com os princípios fundamentais de sua legislação interna, adotará medidas para prevenir a corrupção [...] prever sanções civis, administrativas ou penais eficazes, proporcionadas e dissuasivas em caso de não cumprimento dessas medidas".

Não se pretende como solução a adoção de uma espécie de setencing guidelines ${ }^{69}$ para se definir a pena negociada, mas sim que exis-

68 Eugênio Raul Zaffaroni e José Henrique Pierangeli informam que o Código Penal brasileiro segue o sistema conhecido como das penas "relativamente indeterminadas”, “[...] possibilitando, sempre, uma margem para a consideração judicial, de conformidade com as regras gerais de que é o juiz que deve aplicá-las ao caso concreto. Este sistema opõe-se, na legislação comparada, ao chamado sistema de "penas fixas", nas quais o Código não outorga ao juiz nenhuma faculdade individualizadora” (ZAFFARONI, Eugenio Raúl; PIERANGELI, José Henrique. Manual de Direito Penal brasileiro - parte geralvolume 1. 9a . Ed. São Paulo: Editora Revista dos Tribunais. p. 670).

69 Segundo Diego Zysman Quirós, o sistema da sentencing guidelines nos Estados Unidos "opera em virtude de um elaborado conjunto de direções, lineamentos ou guias penai numéricos (as guidelines propriamente ditas), destinadas a orientar os juízes na imposição de penas precisas para toda configuração que possa ter um fato delitivo. Para isso, contempla uma tábua taxativa de penas na qual se estabelecem 258 posições (ou níveis, mais que escalas) penais que, desde sua origem e por quase duas décadas. [...] Os propósitos manifestos dessa legislação foram erradicar totalmente a discricionariedade judicial e executiva na matéria, 
tam critérios objetivos na dosimetria dos benefícios nos acordos de colaboração, que se eficazes vincularão ao final o magistrado ${ }^{70}$.

Noutro giro, o enorme déficit informacional das agências de repressão acerca do montante do dano provocado pelo acusado colaborador (até mesmo pela natureza difusa e coletiva dos danos) gera um ambiente confortável em omitir intencionalmente o valor real do dano, afinal, de acordo com Thiago Bottino, "não obstante a lei preveja que o acusado se comprometerá a dizer apenas a verdade, trata-se de disposição que, violada, não acarretará consequências graves aos seus autores quando estes estiverem diante de acusações com penas altas"71. Como lembra ainda Bottino, no âmbito da Operação Lava Jato, "constata-se que os benefícios concedidos extrapolam, em muito, as hipóteses previstas em lei, sugerindo um desequilíbrio entre os incentivos para a cooperação e os desincentivos à falsa cooperação"72.

Ademais, frente à adoção de um direito penal de terceira via, quanto mais o pretenso colaborador desviou dos cofres públicos maior será o seu poder de barganha, pois maior será o resultado utilitário no cômputo final para o Ministério Público prestar contas de seu trabalho perante à mídia sensacionalista e à sociedade. Ou seja, quanto maior o valor que o pretenso colaborador puder devolver aos cofres públicos, maiores serão os benefícios penais concedidos. De outra banda, aqueles que menos se beneficiaram dos atos de corrupção têm um poder de bar-

impulsando a coerência, a uniformidade e a transparência na verdadeira duração das condenações impostas" (QUIRÓS, Diego Zysman. Castigo e determinação da pena nos E.U.A. Florianópolis: Empório do Direito. 2017. p. 17-18).

Conforme leciona José Paulo Baltazar Júnior: “levando em consideração o caráter negocial da medida, o juiz está vinculado aos termos do acordo homologado, por si ou por outro magistrado" (BALTAZAR JÚNIOR, José Paulo. Crimes federais. 9. ed. São Paulo: Saraiva, 2014. p. 1297). Aliás, o juiz está vinculado aos termos do acordo homologado, sob pena de violação dos princípios da moralidade e da lealdade (neste sentido: STF, HC 99736 e STJ, HC 97509), o que exige mais cautela do magistrado quando da homologação de acordos de colaboração premiada para se evitar penas desproporcionais.

BOTTINO, Thiago. Colaboração Premiada e incentivos à Cooperação no Processo Penal: Uma Análise Crítica dos Acordos Firmados na "Operação Lava Jato”. Revista Brasileira de Ciências Criminais, São Paulo, Ano 24, vol. 122, ago. 2016. p. 388.

72 BOTTINO, Thiago. Op. cit.. p. 388. 
ganha menor, pois têm pouco a oferecer, e assim muito provavelmente terão prêmios menores. Assim, verifica-se um evidente comprometimento da isonomia material dos investigados, afinal "réus em idêntica situação jurídico-penal receberiam tratamento diferenciado"73.

Neste caso de manifesta violação à isonomia material dos investigados em razão de um acordo de colaboração premiada celebrado, entendemos perfeitamente possível que eventual coautor ou partícipe atingido por esta violação possa impugnar o aludido pacto, até porquê há reflexos na sua esfera jurídica (tratamento desigual). Veja-se que não se trata de questionar o valor probatório do acordo de colaboração premiada, mas sim de se questionar aspectos quantitativos e qualitativos dos benefícios concedidos ao colaborador. Desta feita, entendemos que a posição assentada pelo Pleno do Supremo Tribunal Federal (HC 127.483 - Informativo número 796) no sentido que eventual coautor ou partícipe não possui interesse em impugnar acordo de colaboração premiada deve ser compreendida com reservas.

Por fim, cumpre salientar que o modelo de mercado instaurado gerou até um pedido pelo Ministério Público Federal (Petição 5.210, Distrito Federal - STF) de que parte da quantia recuperada (20\%) à Petrobrás fosse transferida para a União "para destinação aos órgãos responsáveis pela negociação e pela homologação do acordo de colaboração premiada que permitiu tal repatriação". Contudo, acertadamente, o Supremo Tribunal Federal (Ministro Teori Zavascki) julgou improcedente o pedido ministerial, haja vista que a Petrobras é Sociedade de Economia Mista, entidade dotada de personalidade jurídica própria (art. $4^{\circ}$, II, do Decreto Lei 200/1967), cujo patrimônio não se comunica com o da União, sendo que eventuais prejuízos sofridos pela Petrobras, portanto, afetariam apenas indiretamente a União, na condição de acionista majoritária da Sociedade de Economia Mista. Ademais, considerou o Supremo Tribunal Federal que o montante recuperado era insuficiente para reparar os danos supostamente sofridos pela Petrobras em decorrência dos crimes imputados a Paulo Roberto Costa e à organização criminosa que ele integraria.

73 SANTOS, Marcos Paulo Dutra. Colaboração (delação) premiada. Salvador: Juspodivm. 2016. p. 68. 
Margarita Roig Torres critica a utilização do direito penal como instrumento de coação para o pagamento de indenizações, pois a sanção penal ficaria subordinada ao insucesso do acordo. Diante da impossibilidade de celebração de acordo acerca da reparação do dano, o suposto autor do fato será processado. Isso traria, para a referida autora, duas complicações: 1) o patrocínio de prisão por dívidas; 2) a negação do caráter de ultima ratio do direito penal na solução dos conflitos. E, nesta toada, a consequência final seria a violação ao princípio da proporcionalidade ${ }^{74}$.

\section{Considerações Finais}

De acordo com o estudo acima desenvolvido, é possível concluir que as agências de persecução na Operação Lava Jato vêm adotando um direito penal de terceira via no âmbito dos acordos de colaboração premiada envolvendo crimes de corrupção administrativa organizada.

Não se descarta a importância da repatriação de ativos e reparação dos danos causados pela via do acordo de colaboração. Contudo, a racionalidade utilitária-economicista das agências de persecução podem implicar em uma mercantilização do processo penal lesiva ao princípio da legalidade penal, da proporcionalidade e da isonomia na aplicação da pena.

Os benefícios a serem concedidos aos réus colaboradores deveriam seguir estritamente as hipóteses legais, sem intepretações ampliativas, para que se tenham conjuntamente penas criminais efetivas, proporcionais e dissuasivas, conforme determinam alguns documentos internacionais sobre corrupção ratificados pelo Brasil.

Ademais, a falta de fundamentação com relação aos benefícios nos acordos de colaboração e também na sentença (que vem se limitando a acatar o acordo pela análise da eficácia, aplicando a pena nele estabelecida, caso cumprido) gera uma clara afronta ao artigo 93, inciso IX da Constituição Federal, que reza que "todos os julgamentos dos órgãos do Poder Judiciário serão públicos, e fundamentadas todas as decisões, sob

74 TORRES, Margarita Roig. La reparación del daño causado por el delito: aspectos civiles y penales. Valencia: Tirant lo Blanch. 2000. p. 489 
pena de nulidade". Aliás, as penas devem ser fundamentadas para se viabilizar o controle da decisão do magistrado, evitando-se arbitrariedades.

De outro lado, é necessário que haja muita cautela pelos órgãos de persecução quando da celebração dos acordos de colaboração premiada, a fim que não beneficiem determinados réus que angariaram vultuosas quantias em razão de suas práticas corruptas em detrimento daqueles que se beneficiaram infimamente das condutas criminosas. Claro que esta cautela é de difícil de ser implementada na prática, até porque os acordos de colaboração celebrados são instrumentos que servem justamente para melhor apurar os fatos, e só em uma fase avançada da investigação seria possível conclusões mais aprofundadas, quiçá quando da sentença.

Os acordos de colaboração premiada devem sempre respeitar direitos fundamentais dos colaboradores e delatados, garantindo-se imparcialidade judicial e o compromisso do Ministério Público com a justiça.

\section{REFERÊNCIAS}

AGUIAR, Júlio César de; FONSECA, Cibele Benevides Guedes da; TABAK, Bejnamin Miranda. A colaboração premiada compensa? Brasília: Núcleo de Estudos e Pesquisas/CONLEG/Senado. Agosto/2015 (Texto para Discussão $n^{\circ}$ 181). Disponível em: <www.senado.leg.br/estudos>. Acesso em 08 de janeiro de 2017.

ALMEIDA, Andreia Alves de; PEREIRA, Fabíola de Jesus. A Eficácia da Colaboração Premiada no Combate à Corrupção: O Efeito Dominó na Operação Lava Jato. in: PRANDO, Camila Cardoso de Mello; STAFFEN, Márcio Ricardo; RIBEIRO, Diaulas Costa (Org.). Direito Penal e Constituição. Florianópolis: CONPEDI, 2016

AMBOS, Kai; MALARINO, Ezequiel; VASCONCELOS, Eneas Romero (Coord.). Polícia e investigação no Brasil. Brasília: Gazeta Jurídica, 2016.

ARAÚJO, Galucio Roberto Brittes; CUNHA FILHO, Alexandre J. Carneiro da; LIVIANU, Roberto; PASCOLATI JÚNIOR, Ulisses Augusto. 48 visões sobre a corrupção. São Paulo: Quarter Latim, 2016.

BALTAZAR JÚNIOR, José Paulo. Crimes federais. 9. ed. São Paulo: Saraiva, 2014. BECKER, Gary Stanley. The Economic Approach to Human Behavior. Universidade de Chicago Press. 1978.

BOTTINI, Pierpaolo Cruz. Enfrentamento de excessos não autoriza uso arbitrário das leis. 17 de outubro de 2013. Disponível em: <http://www.conjur.com. 
br/2013-out-17/pierpaolo-bottini-enfrentamento-excessos-nao-autoriza-usoarbitrario-leis>. Acesso em 07 de fevereiro de 2017.

BOTTINO, Thiago. Colaboração Premiada e incentivos à Cooperação no Processo Penal: Uma Análise Crítica dos Acordos Firmados na "Operação Lava Jato". Revista Brasileira de Ciências Criminais, São Paulo, Ano 24, vol. 122, ago. 2016.

DALLAGNOL, Deltan. As luzes da delação premiada: A colaboração do delator oferece ao investigador a oportunidade de iluminar o labirinto da corrupção e descobrir os melhores caminhos para desvendá-lo. 2015. Disponível em: <http:// epoca.globo.com/tempo/noticia/2015/07/luzes-da-delacao-premiada.html>. Acesso em: 07 mar. 2016.

FALCÃO, Márcio. Stf rejeita anular acordo de delação premiada de Youssef na Operação Lava Jato. Folha de São Paulo, 27 de agosto de 2105. Disponível em: http://www1.folha.uol.com.br/poder/2015/08/1674345-maioria-do-stf-votacontra-anulacao-de-depoimentos-de-alberto-youssef.shtml. Acesso em 25 de setembro de 2016.

FERRO, Ana Luiza Almeida. Crime Organizado e Organizações Criminosas Mundiais. Curitiba: Juruá, 2009.

GAROUPA, Nuno; KLERMAN, Daniel. Corruption and The Optimal Use of Nonmonetary Sanctions. Los Angeles: University of Southern California Law School (Cleo Research Paper Series Law \& Economics Research Paper Series - Paper $\mathrm{n}^{\circ} \mathrm{C} 01-4$ e 1-9), disponível em: <http://papers.ssrn.com.abstract_ id=276117 >. Acesso em 14 de junho de 2015.

GOMES, Luiz Flávio. A Impunidade da Macrodelinquência Econômica desde a Perspectiva Criminológica da Teoria da Aprendizagem. in: DOTTI, René Ariel; PRADO, Luiz Regis (Org.). Doutrinas essenciais de Direito Penal Econômico e da Empresa. Vol. I. São Paulo: Revista dos Tribunais. 2011.

GRECO, Rogério. Curso de Direito Penal - parte geral. Vol. 1. 18 ed. Niterói: Impetus. 2016.

HASSEMER, Winfried. Desenvolvimentos previsíveis na dogmática do Direito Penal e na Política Criminal. Revista Eletrônica de Direito Penal e Política Criminal - UFRGS, vol. 1, $\mathrm{n}^{\circ}$ 1, 2013.

MANDARINO, Renan Posella. Aspectos penais controversos da colaboração premiada. São Paulo: IASP, 2016.

MEGALEI, Bela. PF se opõe a novas delações premiadas na Lava Jato. São Paulo: Folha de São Paulo. 04 de Outubro de 2016. Disponível em: < http://www1. folha.uol.com.br/poder/2016/10/1819588-pf-se-opoe-a-novas-delacoespremiadas-na-lava-jato.shtml>. Acesso em 07 de janeiro de 2017.

MENDES, Soraia da Rosa; BARBOSA, Kássia Cristina de Souza. Anotações sobre o requisito da voluntariedade e o papel do/a juiz/a em acordos de colaboração 
premiada envolvendo investigados/as e /ou réus/és presos/as provisoriamente. In: MENDES, Soraia da Rosa. A delação/colaboração premiada em perspectiva. Brasília: IDP. 2016.

NEUMANN, Ulfrid. Alternativas al derecho penal (Critica e justificación del derecho penal en el cambio de siglo). El análisis crítico de la Escuela de Frankfurt. Cuenca: Editones de la Universidade de Castilla-La Mancha. 2003.

NUNES, Leandro Bastos. Operação Lava Jato. Publicado em 01/2017. Disponível em: <https://jus.com.br/artigos/54880/operacao-lava-jato $>$. Acesso em: 03 de janeiro de 2017.

PEREIRA, Flávio Cardoso. Crime organizado e sua infiltração nas instituições governamentais. São Paulo: Atlas, 2015.

PRADO, Cláudio Amaral do. Despenalização pela reparação de danos: a terceira via. Leme: J.H. Mizuno, 2005.

PULITANÒ, Domenico. Tecniche premiali fra diritto e processo penale. Rivista Italiana di Diritto e Procedura Penale. Milano, a. 29, nova série, fasc. 4. Ott/dic., 1986.

QUEIROZ, Paulo (Coord.) Direito Penal - parte especial. Vol. 2. $3^{\text {a }}$ ed. Salvador: Juspodivm, 2016.

QUIRÓS, Diego Zysman. Castigo e determinação da pena nos E.U.A.: um estudo sobre as United States sentencing guidelines. Florianópolis: Empório do Direito, 2017.

TABAK, Benjamin Miranda. A Análise Econômica do Direito - Proposições Legislativas e políticas públicas. Revista de Informação Legislativa / Senado Federal, Subsecretaria de edições Técnicas - Ano 52, nº 205, jan./mar. 2015.

ROSA, Alexandre Morais da. Guia Compacto do Processo Penal Conforme a Teoria dos Jogos. Florianópolis: Empório do Direito, 2016.

ROXIN, Claus. Fines de la pena y reparación del daño: de los delitos y de a las víctimas. Tradução española de Julio Maiery Elena Carranza. Buenos Aires: Ad Hoc, 1992.

SANDEL, Michael J. O que o dinheiro não compra: os limites morais do mercado. Rio de Janeiro: Civilização Brasileira, 2012.

SANTOS, Marcos Paulo Dutra. Colaboração (delação) premiada. Salvador: Juspodivm, 2016.

SILVA, Gustavo Henrique de Souza e. O princípio da legalidade e o direito penal econômico: análise sob a perspectiva do Estado Democrático de Direito. 2011. Dissertação - Universidade Federal de Minas Gerais. Faculdade de Direito.

SUMALLA, Josep M. Tamarit. La Reparación da la Víctima en el Derecho Penal (Estudio y Crítica de las Nuevas Tendencias Políticos-Criminales). Barcelona: 
Edición Centre d'Etudies Jurídicis i Formació Especializtada de la Generalitat de Catalunya \& Fundació Jaume Callís. 1993.

TORRES, Margarita Roig. La reparación del daño causado por el delito: aspectos civiles y penales. Valencia: Tirant lo Blanch. 2000.

VASCONCELLOS, Vinicius Gomes de. Barganha e justiça criminal negocial: análise das tendências de expansão dos espaços do consenso no processo penal brasileiro. São Paulo: IBCCRIM. 2015.

ZAFFARONI, Eugenio Raúl; PIERANGELI, José Henrique. Manual de Direito Penal brasileiro - parte geral- volume 1. 9ª . Ed. São Paulo: Revista dos Tribunais. 2011.

Dados do processo editorial

(http://www.ibraspp.com.br/revista/index.php/RBDPP/about/editorialPolicies)

- Recebido em: 08/01/2017

- Controle preliminar e verificação de plágio: 08/01/2017

- Avaliação 1: 12/01/2017

- Avaliação 2: 25/01/2017

- Decisão editorial preliminar: 25/01/2017

- Retorno rodada de correções 1: 08/02/2017

- Decisão editorial 2: 09/02/2017

- Retorno rodada de correções 2: 09/02/2017

- Decisão editorial final: 09/02/2017

\section{Equipe editorial envolvida}

- Editor-chefe: 1 (VGV)

- Editora-associada: 1 (SRM)

- Revisores: 2

\section{COMO CITAR ESTE ARTIGO:}

SILVA, Marcelo R. A colaboração premiada como terceira via do direito penal no enfrentamento à corrupção administrativa organizada. Revista Brasileira de Direito Processual Penal, Porto Alegre, vol. 3, n. 1, p. 285-314, jan./abr. 2017. https://doi.org/10.22197/rbdpp.v3i1.50

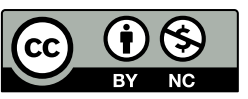

Esta obra está licenciada com uma Licença Creative Commons Atribuição-NãoComercial 4.0 Internacional. 